\title{
P02.116. The relationship between deqi and the effect of acupuncture
}

\author{
Y Choi, S Cho*, J Lee, W Moon, D Yoo \\ From International Research Congress on Integrative Medicine and Health 2012 \\ Portland, Oregon, USA. 15-18 May 2012
}

\section{Purpose}

There is an experimental study that suggests deep needling with rotation produces higher acupuncture needling sensation than superficial needling with mock rotation. Also, there are opposing results about the relationship between acupuncture needling sensation and analgesic effect. In this study, we intend to investigate the relationship between acupuncture needling sensation and analgesic effect according to acupuncture stimulation.

\section{Methods}

Fifty healthy volunteers received 3 different forms of acupuncture in a single-blinded crossover design; these included superficial needling $(0.3 \mathrm{~cm})$, deep needling $(2$ $\mathrm{cm})$, and needling with bi-directional rotation. The time between the interventions was more than 48 hours. All forms of acupuncture were applied unilaterally on the left leg at standard acupuncture points: SP 6, SP 9, ST 36, and GB 39. The effects of acupuncture were evaluated using pressure pain threshold. Each participant completed the Subjective Acupuncture Sensation Scale (SASS).

\section{Results}

Both SASS and increases in pressure pain threshold were largest in needling with rotation followed by deep needling and superficial needling. An ANOVA analysis was carried out in order to see whether there is a significant difference; both had $\mathrm{p}$ values lower than 0.001 . Also, the correlation between the sum of SASS and changes in pressure pain threshold was calculated using Spearman's rho; there was a significant correlation $(\mathrm{p}=0.027)$.

\section{Conclusion}

Acupuncture needling sensation and pressure pain threshold increased according to depth and rotation of

Hospital of Korean Medicine, Kyung Hee University Medical Center, Seoul, Republic of Korea

(c) 2012 Choi et al; licensee BioMed Central Ltd. This is an Open Access article distributed under the terms of the Creative Commons Attribution License (http://creativecommons.org/licenses/by/2.0), which permits unrestricted use, distribution, and reproduction in any medium, provided the original work is properly cited. acupuncture. There is a significant correlation between acupuncture needling sensation and increases in pressure pain threshold. It seems that deqi plays an important role in revealing the effect of acupuncture.

Published: 12 June 2012

doi:10.1186/1472-6882-12-S1-P172

Cite this article as: Choi et al:: P02.116. The relationship between deqi and the effect of acupuncture. BMC Complementary and Alternative Medicine 2012 12(Suppl 1):P172.
Submit your next manuscript to BioMed Central and take full advantage of:

- Convenient online submission

- Thorough peer review

- No space constraints or color figure charges

- Immediate publication on acceptance

- Inclusion in PubMed, CAS, Scopus and Google Scholar

- Research which is freely available for redistribution 